\title{
Anatolian Shepherd Dog
}

National Cancer Institute

\section{Source}

National Cancer Institute. Anatolian Shepherd Dog. NCI Thesaurus. Code C54047.

The Anatolian Shepherd Dog is a large dog similar to the Great Pyrenees and the Kuvasz, but more slender. The head is large and the muzzle is a bit shorter than the skull, with a blunt profile. Triangular, pendant ears are rather small with rounded tips. The back is short relative to leg length. The short or rough double coat is generally fawn with a black mask. Height: 26-30 inches (66-76 cm.) Weight: 90-150 pounds (41-68 kg.) 